\title{
A study on diagnosis and management of arteriovenous malformation of uterus
}

\author{
Nidhi B. Patel*, Sapana R. Shah, Purvi M. Parikh, Tanmay J. Chudasama
}

Department of Obstetrics and Gynecology, SVP Hospital and NHL Medical College, Ahmedabad, Gujarat, India

Received: 24 April 2020

Accepted: 29 May 2020

*Correspondence:

Dr. Nidhi B. Patel,

E-mail: nidhibhadani1994@gmail.com

Copyright: (C) the author(s), publisher and licensee Medip Academy. This is an open-access article distributed under the terms of the Creative Commons Attribution Non-Commercial License, which permits unrestricted non-commercial use, distribution, and reproduction in any medium, provided the original work is properly cited.

\begin{abstract}
Background: Arteriovenous malformation is abnormal connection between an organ's arterial and venous circulation. In acquired AVM, history of uterine procedure seems inevitable. Their clinical feature is usually vaginal bleeding. It is diagnosed by 2-D ultrasonography combined with colour doppler. Most of the time they resolve spontaneously; however, if left untreated, uterine artery embolization or hysterectomy comes in hand. The purpose of this study was to evaluate the role of TVUS and colour doppler in the diagnosis and follow-up of treated cases of uterine AVM. This study also aims to evaluate different modalities to manage uterine AVM.

Methods: This was a retrospective study done at tertiary care centre from January 2018 to December 2019 to assess the presentation, treatment, and clinical pictures of patients with uterine AVM that were diagnosed with TVUS. Authors reviewed both (1) clinical data (2) ultrasound data of patients. The diagnostic criteria were "subjective" with a rich vascular network in the myometrium with the use of colour Doppler images and "objective" with a high PSV of $20 \mathrm{~cm} / \mathrm{sec}$ in the vascular web.

Results: Thirteen patients met the diagnostic criteria mentioned above. Out of that $100 \%$ presented with on and off bleeding per vaginum. Recent and remote history of uterine procedures were in found in $84.6 \%(n=11)$ of cases. UAE was done in $53.8 \%(n=7)$ cases. Thirty-three $(33 \%)(n=5)$ cases spontaneously resolved when closely monitored with serial imaging and serum beta- HCG levels. Hysterectomy was needed in 7.4\% $(n=1)$ of patients of AVM.

Conclusions: Uterine AVM occurred after unsuccessful pregnancies or uterine procedures. Triage of patients for expectant treatment, hormonal treatment vs intervention with uterine artery embolization based on their clinical status, which was supplemented by objective measurements of blood velocity measurement in the AVM, appears to be a good predictor of outcome.
\end{abstract}

Keywords: Arteriovenous malformation, Curettage, Uterine artery embolization, Uterus

\section{INTRODUCTION}

Arteriovenous malformation is a pathologic phenomenon describes as abnormal connections between arterial and venous end of circulation which was first described by Dubreil and Loubat in 1926 as "aneurysme cirsoide de l'uterus." They are vascular lesions that may cause life threatening gynaecologic haemorrhage.,3 They can occur when the thin wall of the abnormal vessels is disrupted either naturally after menstruation or artificially after instrumentation. ${ }^{4,5}$ AVMs are classified broadly as either congenital or acquired. ${ }^{5}$ Acquired uterine AVMs are usually traumatic and result from previous uterine surgery including diagnostic or therapeutic curettage, caesarean delivery, or myomectomy. ${ }^{6-8}$ The clinical symptoms of uterine AVMs can appear gradually or suddenly, with patients most commonly presenting with heavy or irregular vaginal bleeding after a miscarriage, uterine surgery, or treated or untreated CSP. The natural history is variable; some cases slowly revert to normal circulation, and the condition disappears over a period of weeks to months, although some persist without 
regression, which puts the patient at higher risk of haemorrhage. AVMs represent $12 \%$ of all pelvic and intraperitoneal haemorrhages; in $30 \%$ of cases, a blood transfusion is necessary. ${ }^{9-11}$ With significant bleeding, treatment is of the essence, often in the form of uterine artery embolization (UAE). Importantly, curettage for patients with heavy vaginal bleeding because of an AVM may exacerbate the bleeding and may be life-threatening when the diagnosis of AVM has not been made before the intervention. ${ }^{12}$ Angiography became the "gold standard "diagnostic method." Most recently, transvaginal ultrasound scanning (TVUS) has emerged as an efficient, simple, and accessible diagnostic modality to detect and follow the vascular pattern of the AVM with the use of blood velocity blood flow indices. ${ }^{12}$ The aim of this study is to review the value of TVUS in the diagnosis and treatment of suspected uterine AVMs to outline the disease's natural history.

\section{METHODS}

This study is a retrospective review of medical records and ultrasound images to assess the presentation, diagnosis, management, treatment, and clinical outcomes of patients with uterine AVMs. All patients who presented to tertiary care centre from January 2018 to December 2019, and were diagnosed with pregnancy related uterine AVM on 2-dimensional TVUS were eligible for inclusion in the study. All patients are first examined with the grayscale mode followed by colour/power Doppler interrogation. There were no restrictions on age or racial/ethnic origins for inclusion. Criteria for the sonographic diagnosis were (1) unusual, tubular, tortuous, anechoic structures seen by 2dimensional grayscale ultrasound imaging on sagittal and/or transverse section of the uterus, which subjectively reveal an unusually rich vascularity with tortuousappearing blood vessels that are concentrated in a small area of myometrium adjacent to the uterine cavity, with or without clearly visible products of conception (POC) that are detected by grayscale ultrasound imaging followed by colour or power Doppler imaging and (2) objectively a demonstration of high velocity blood flow within the vascular "web" with a peak systolic velocity (PSV) of $>20 \mathrm{~cm} / \mathrm{sec}$. Authors used the highest PSV value to represent the AVM. Information to be reviewed included (1) TVUS data (images, measured dimensions, Doppler velocities, and resistive indices) and (2) clinical data (patient age, reproductive status, surgical history, clinical presentation, inciting event or procedure, clinical course, time intervals that included detection-to resolution or detection-to-treatment, and treatment rendered). Patients selected for UAE based on clinical status or sonographic findings were referred to the department of interventional radiology. An operator performed the diagnostic angiogram using digital subtraction angiography, followed by the therapeutic intervention that consisted of embolization of the feeding vessel. The diagnostic and therapeutic intervention was always performed in bilateral uterine arteries.

Table 1: Patient demographics, clinical data and outcome of the 13 patients with EMV/AVM.

\begin{tabular}{|c|c|c|c|c|c|c|c|c|c|}
\hline Case & Age & $\mathbf{G} / \mathbf{P}$ & $\begin{array}{l}\text { Clinical } \\
\text { presentation }\end{array}$ & $\begin{array}{l}\text { Surgical } \\
\text { historylMTP } \\
\text { pills }\end{array}$ & $\begin{array}{l}\text { PSV } \\
(\mathbf{C M} / \mathbf{S})\end{array}$ & UAE & Transfusion & Clinical course & Outcome \\
\hline 1 & 22 & G2P0A1L0 & $\begin{array}{l}\text { Caesarean scar } \\
\text { pregnancy }\end{array}$ & $\mathrm{D}$ and $\mathrm{E}$ & 90 & Yes & Yes & $\begin{array}{l}\text { Serial } \\
\text { imaging+UAE }\end{array}$ & Resolution \\
\hline 2 & 24 & G2P0A1L0 & $\begin{array}{l}\text { Incomplete } \\
\text { abortion after } \\
\text { MTP pills }\end{array}$ & MTP pills & 88 & Yes & No & $\begin{array}{l}\text { Serial } \\
\text { imaging+UAE }\end{array}$ & Resolution \\
\hline 3 & 18 & G1P0A0L0 & $\begin{array}{l}\text { Incomplete } \\
\text { abortion }\end{array}$ & $\mathrm{D}$ and $\mathrm{E}$ & 78 & No & No & $\begin{array}{l}\text { Serial imaging } \\
+ \text { B-HCG+iron } \\
\text { tablets }\end{array}$ & Resolution \\
\hline 4 & 33 & G4P2A1L2 & Missed abortion & $\mathrm{D}$ and $\mathrm{E}$ & 90 & No & No & $\begin{array}{l}\text { Serial imaging } \\
+\mathrm{B}-\mathrm{HCG}+\mathrm{iron} \\
\text { tablets+oc pills }\end{array}$ & Resolution \\
\hline 5 & 20 & G2P1A0L1 & Missed abortion & $\mathrm{D}$ and $\mathrm{E}$ & 77 & No & No & $\begin{array}{l}\text { Serial imaging } \\
+\mathrm{B}-\mathrm{HCG}+ \\
\text { iron tablets }\end{array}$ & Resolution \\
\hline 6 & 26 & G3P1A1L1 & $\begin{array}{l}\text { Incomplete } \\
\text { abortion }\end{array}$ & $\mathrm{D}$ and $\mathrm{E}$ & 90 & Yes & No & $\begin{array}{l}\text { Serial } \\
\text { imaging+ UAE }\end{array}$ & Resolution \\
\hline 7 & 27 & G3P0A2L0 & Missed abortion & $\mathrm{D}$ and $\mathrm{E}$ & 70 & No & No & $\begin{array}{l}\text { Serial imaging } \\
+\mathrm{B}-\mathrm{HCG}+ \\
\text { iron tablets }\end{array}$ & Resolution \\
\hline 8 & 34 & G1P1A0L1 & Missed abortion & $\mathrm{D}$ and $\mathrm{E}$ & 86 & Yes & Yes & $\begin{array}{l}\text { Serial imaging } \\
\text { + UAE }\end{array}$ & Resolution \\
\hline 9 & 25 & GOPOLO & $\begin{array}{l}\text { Increased } \\
\text { menstrual } \\
\text { bleeding PV }\end{array}$ & MTP pills & 68 & Yes & No & $\begin{array}{l}\text { Serial imaging } \\
\text { + B-HCG+iron } \\
\text { tablets }\end{array}$ & Resolution \\
\hline 10 & 19 & G2P0A1L0 & Missed & $\mathrm{D}$ and $\mathrm{E}$ & 90 & Yes & No & Serial imaging & Resolution \\
\hline
\end{tabular}




\begin{tabular}{|lllllllll|l|} 
Case & Age & G/P & $\begin{array}{l}\text { Clinical } \\
\text { presentation } \\
\text { abortion }\end{array}$ & $\begin{array}{l}\text { Surgical } \\
\text { historylMTP } \\
\text { pills }\end{array}$ & $\begin{array}{l}\text { PSV } \\
(\text { CM/S })\end{array}$ & UAE & Transfusion & Clinical course & Outcome \\
\hline 11 & 21 & G2P1A1L1 & $\begin{array}{l}\text { Incomplete } \\
\text { abortion }\end{array}$ & D and E & 78 & Yes & No & $\begin{array}{l}\text { Serial imaging } \\
+ \text { UAE }\end{array}$ & Resolution \\
\hline 12 & 28 & G3P2A0L2 & Missed abortion & D and E & 70 & No & Yes & Hysterectomy & Hysterectomy \\
\hline 13 & 22 & G2P0A1L0 & Post D and E & D and E & 80 & Yes & No & $\begin{array}{l}\text { Serial imaging } \\
+ \text { UAE }\end{array}$ & Resolution \\
\hline
\end{tabular}

\section{RESULTS}

There were 13 patients who met the diagnostic criteria of uterine AVM. Table 1 includes their mean age, gravidity, parity, and clinical diagnoses. Mean age was 24.4 years (range, 18-33 years). All patients presented with bleeding per vaginum. Overall surgical history included 11 patients $(84.6 \%)$ with either recent or remote uterine surgery and 2 patients $(15.4 \%)$ had history of ingestion of MTP pills. Eleven patients have undergone curettage $(84.6 \%)$. Ultra sound were performed every 2 weeks or, in very few cases until resolution. Treatment was varied and included: expectant management alone with serial ultrasound scans and serial serum human chorionic gonadotropin until complete resolution $(n=4)(33.3 \%)$, hormonal treatment (combined oc pills) were given in 1 patient $(\mathrm{n}=1)(7.6 \%)$, UAE $(\mathrm{n}=7)(53.8 \%)$, hysterectomy $(n=1)(7.6 \%)$. The overall episode time from diagnosis to resolution of the AVM was 2-15 weeks. Seven patients who required UAE, resolved after the procedure and required no further intervention. Embolization was able to stop the bleeding in these patients and lead to the resolution of the vascular pattern as judged by an ultrasound examination. Methotrexate was given to 1 of the 11 patients. Out of seven cases of patients who had history of D and E, 1 case was having undiagnosed CSP and had received one dose of methotrexate in private hospital. Patient presented with profuse vaginal bleeding at tertiary care centre, severe anaemia and USG showed AVM at CS site of $4 \times 3 \mathrm{~cm}$. Patient was managed with $\mathrm{B} / \mathrm{L}$ UAE and serial imaging with USG. Hysterectomy was performed in 1 patient in the series where $\mathrm{D}$ and $\mathrm{E}$ was attempted and there was profuse haemorrhage requiring hysterectomy. Three patients in the series required a blood transfusion (23\%): the first for intractable bleeding before hysterectomy, two were for symptomatic anaemia before undergoing UAE.

\section{DISCUSSION}

AV malformation is an abnormal connection between arterial and venous circulation system without intervening capillary bed. ${ }^{2}$ Pelvic AV malformation is a rare cause of heavy and life-threatening vaginal bleeding. Mean age in the present study is 24.4 years. Yoon et al and Ilan et al in their study identified the mean age of their study population as 33.5 years and 31.8 years respectively. ${ }^{13,14}$ In this study $84.6 \%$ cases had history of recent or remote uterine procedures. Similarly, Yoon et al and Ilan et al had $93 \%$ and $70 \%$ cases with such history respectively. ${ }^{13,14} \mathrm{UAE}$ was modality of treatment successfully treating $53.8 \%$ of cases in this study without requiring further intervention thus having success rate of $100 \%$. Yoon et al noted $100 \%$ cases requiring UAE out of which $61 \%$ cases didn't require any further intervention after primary UAE. Out of $39 \%$ cases remaining who failed to respond to UAE, required further intervention like repeat embolization, medical treatment with ocpills, danazol, methotrexate, occlusion of internal iliac artery and hysterectomy as a last resort. ${ }^{13}$ Ghai at al mentioned $93 \%$ cases being resolved with repeat UAE, only $6.6 \%$ cases were required to undergo hysterectomy due to presence of intractable bleeding after several cycles of UAE. ${ }^{15}$ Wang et al reported $83 \%$ cases being successfully treated with first attempt of embolization. ${ }^{16}$ Repeat cycles of UAE were required in $5.3 \%$ cases, proving success rate of $88 \%$ of the cases. No postembolization complications were noted in present study. Ghai et al noted $26 \%$ cases having moderate pelvic pain post embolization being managed by analgesia and $13 \%$ cases having post-embolization fever being resolved spontaneously. ${ }^{15}$ Similarly in Wang et al $16 \%$ cases were having post-embolization pelvic pain and fever which were treated with analgesics and fever being resolved spontaneously. ${ }^{16}$ In present study $33 \%$ cases resolved spontaneously with serial imaging and serum HCG levels being closely monitored which was comparable to Elan et al $(48 \%) .{ }^{14}$ After intractable bleeding per vaginum, hysterectomy was done in $7.4 \%$ in present study. In yoon et al $10 \%$ cases had undergone hysterectomy due to failure of repetitive UAE to resolve AVM. Blood transfusions were necessary in $23 \%$ cases in present study comparable to elan et al $(11 \%) .{ }^{14}$

\section{CONCLUSION}

AVM, a relatively rare phenomenon, occurs as a consequence of intrauterine treatment procedures and usually has heavy vaginal bleeding. Clinicians should be familiar and be aware that the sonographic diagnosis can be based only by Doppler interrogation of the uterus. Spontaneous abortions, sharp uterine curettage and ingestion of MTP pills risks for an AVM.

Although in the past uterine artery angiography was the gold standard for diagnosis, presently transvaginal grey scale and colour Doppler ultrasound evaluation is 
emerging as the simplest, best, and most cost-effective diagnostic imaging modalities. Triage of patients for either conservative follow up or treatment with UAE may be based on their clinical picture and by measurement of blood velocity in the area of AVM. Prevention of potentially life-threatening haemorrhage and preservation of fertility are some of the main advantages that embolization for AVMs has over more definitive surgical options, such as hysterectomy. Gynaecologists should be aware of the existence of AVM and rule it out before performing a curettage or aspiration for prolonged uterine bleeding.

\section{Funding: No funding sources}

Conflict of interest: None declared

Ethical approval: The study was approved by the Institutional Ethics Committee

\section{REFERENCES}

1. Dubreuil G, Loubat E. Aneurysme cirsoide del'uterus. Ann Anat Pathol. 1926;3:697-718.

2. Hoffman MK, Meilstrup JW, Shackelford DP, Kaminski PF. Arteriovenous malformations of the uterus: an uncommon cause of vaginal bleeding. Obstet Gynecol Surv. 1997;52:736-40.

3. Lui MW, Shek NW, Li RH, Chu F, Pun TC. Management of heterotopic caesarean scar pregnancy by repeated transvaginal ultrasonographic-guided aspiration with successful preservation of normal intrauterine pregnancy and complicated by arteriovenous malformation. Eur J Obstet Gynecol Reprod Biol. 2014;175:209-10.

4. Diwan RV, Brennan JN, Selim MA, McGrew TL, Rashad FA, Rustia MU, et al. Sonographic diagnosis of arteriovenous malformation of the uterus and pelvis. J Clin Ultrasound. 1983;11:295-8.

5. Vogelzang RL, Nemcek AA, Skrtic Z, Gorrell J, Lurain JR. Uterine arteriovenous malformations: primary treatment with therapeutic embolization. J Vasc Interv Radiol. 1991;2:517-22.

6. Halperin R, Schneider D, Maymon R, Peer A, Pansky M, Herman A. Arteriovenous malformation after uterine curettage: a report of 3 cases. J Reprod Med. 2007;52:445-9.

7. Peitsidis P, Manolakos E, Tsekoura V, Kreienberg R, Schwentner L. Uterine arteriovenous malformations induced after diagnostic curettage: a systematic review. Arch Gynecol Obstet. 2011;284:1137-51.

8. Takeda A, Koike W, Imoto S, Nakamura H. Conservative management of uterine artery pseudoaneurysm after laparoscopic-assisted myomectomy and subsequent pregnancy outcome: case series and review of the literature. Eur J Obstet Gynecol Reprod Biol. 2014;182:146-53.

9. McIvor J, Cameron EW. Pregnancy after uterine artery embolization to control haemorrhage from gestational trophoblastic tumour. $\mathrm{Br} \mathrm{J}$ Radiol. 1996;69:624-9.

10. Newlands ES, Bagshawe KD, Begent RH, Rustin GJ, Holden L, Dent J. Developments in chemotherapy for medium- and high-risk patients with gestational trophoblastic tumours. BJOG. 19791984;1986(93):63-9.

11. Manolitsas T, Hurley V, Gilford E. Uterine arteriovenous malformation: a rare cause of uterine haemorrhage. Aust N Z J Obstet Gynaecol. 1994;34:197-9.

12. Timmerman D, Wauters J, Van Calenbergh S, Van Schoubroeck D, Maleux G, Van Den Bosch T, et al. Color Doppler imaging is a valuable tool for the diagnosis and management of uterine vascular malformations. Ultrasound Obstet Gynecol. 2003;21:570-7.

13. Yoon DJ, Jones M, Al Taani J, Buhimschi C, Dowell JD. A systematic review of acquired uterine arteriovenous malformations: pathophysiology, diagnosis, and transcatheter treatment. Am J Perinatol Reports. 2016;6(01):e6-14.

14. Timor-Tritsch IE, Haynes MC, Monteagudo A, Khatib N, Kovács S. Ultrasound diagnosis and management of acquired uterine enhanced myometrial vascularity/arteriovenous malformations. Am J Obstet Gynecol. 2016;214(6):731-e1.

15. Ghai S, Rajan DK, Asch MR, Muradali D, Simons ME, TerBrugge KG. Efficacy of embolization in traumatic uterine vascular malformations. J Vascular Intervent Radiol. 2003;14(11):1401-8.

16. Wang Z, Chen J, Shi H, Zhou K, Sun H, Li X, et al. Efficacy and safety of embolization in iatrogenic traumatic uterine vascular malformations. Clinical Radiol. 2012;67(6):541-5.

Cite this article as: Patel NB, Shah SR, Parikh PM, Chudasama TJ. A study on diagnosis and management of arteriovenous malformation of uterus. Int J Reprod Contracept Obstet Gynecol 2020;9:2878-81. 